\title{
Implementing Sustainable Supply Chain in PLM
}

\author{
Maria Bonvehí Rosich ${ }^{1}$, Julien Le Duigou, ${ }^{2, *}$, and Magali Bosch-Mauchand ${ }^{2}$ \\ ${ }^{1}$ Universitat Politècnica de Catalunya - ETSEIB \\ ETSEIB - Av. Diagonal, 647 - 08028 Barcelona Spain \\ maria.bnvhegmail.com \\ ${ }^{2}$ Université de Technologie de Compiègne \\ UTC - Rue du Docteur Schweitzer - 60200 Compiègne France \\ \{magali.bosch, julien.le-duigou\}@utc.fr
}

\begin{abstract}
Sustainable supply chain has received growing attention in recent years. Due to the lack of relevant data to permit a credible analysis of sustainable supply chain, it is quite hard to propose an analytic method to guide sustainable supply chain strategies. Product Lifecycle Management (PLM) has provided companies with useful software to manage information using product as a central element. It consolidates all the information about product but also about production and distibution. For this reason it is interesting to integrate specific information in PLM systems necessary to manage sustainable supply chain and define a methodology to implement it. The proposal is a methodology based on a four steps process to guide companies which want to start a sustainable development using the information from their PLM tools such as Enterprise Resource Planning and/or Product Data Management.
\end{abstract}

Keywords: Sustainable Supply Chain, Product Lifecycle Management, Integration.

\section{Introduction}

Nowadays Supply Chain Management (SCM) is a crucial activity of a company to insure competitivity. In todays indsutrial context, suppliers, companies and customers are linked by numerous information and material flows (Seuring and Müller, 2008). For this reason SCM is an essential system for companies around the world. However due to the introduction of sustainability performance in companies SCM is evolving. In recent years supply chain has been extended and the complexity of networks has moved exponentially (Sekhari et al., 2010). All these changes and the globalization in demands have produced an impact on environmental, social and economic performance. Therefore sustainability is becoming one of companies' worries and they are trying to implement new systems in their process to achieve this objective. Among the multiple options which can be implemented one is the sustainable Supply Chain Management (sSCM).

\footnotetext{
* Corresponding author.
}

C. Emmanouilidis, M. Taisch, D. Kiritsis (Eds.): APMS 2012, Part II, IFIP AICT 398, pp. 168-175, 2013.

(C) IFIP International Federation for Information Processing 2013 
The sSCM is the integration of sustainable considerations into supply chain policies, programs and actions (Large and Gimenez Thomsen, 2011). One of the issues for sustainable supply chain analysis is the lack of relevant data available. Indeed the data available from the open database are not specific to the compagnies products and processes (Ketikidis et al., 2008). A possible solution to assess and improve the sustainable performances of the supply chain is to integrate the Product Lifecycle Management data into the supply chain management analysis. PLM "is defined as a concept for the integrated management of product related information through the entire product lifecycle" (Schuh et al., 2008). PLM gives necessary tools to a company in order to manage its products across their lifecycle, this management is essential to accomplish the company's aims.

This paper begins with a literature review to define an initial framework. Then the methodology is explained using four steps, and finally a conclusion provides lectors with a summary and future improvement for the methodology.

\section{$2 \quad$ Literature Review}

Sustainability has been defined as "the development that meets the needs of the present without compromising the ability of future generations to meet their needs" since the publication of the Brundtland Report in 1987 (Sekhari et al., 2010). Sustainable development should ideally improve the quality of life without expending the earth's resources beyond its capacity. The achievement of sustainable development requires that companies, governments and individuals take actions, i.e., changing consumption habits, production behaviors, setting policies and changing practices (Remmen et al., 2007).

Sustainability has three dimensions (Fig. 1) named "the triple bottom line" by Elkington in 1997. It implies that industries have to expand their economic objectives to include environmental and social dimensions, in order to achieve "sustainable business" (Remmen et al., 2007).

To fully attempt sustainable development, companies could not work alone anymore. They have to integrate their customers and suppliers in their development, i.e. think at the supply chain's level. "SC encompasses all activities associated with the flow and transformation of goods from raw materials stage (extraction), through to the end user, as well as the associated information flows; material and information flow both up and down the supply chain" (Seuring and Müller, 2008). Mentzer et al. (2001) defined SCM as, "the systemic, strategic coordination of the traditional business functions and the tactics across these business functions within a particular company and across businesses within the supply chain, for the purposes of improving the long-term performance of the individual companies and the supply chain as a whole', (Ageron et al., 2011). 
Many articles have linked sustainability with SCM (Seuring and Müller, 2008; Sekhari et al., 2010; Large and Gimenez Thomsen, 2011; Ageron et al., 2011; Global Commerce initiative and Capgemini, 2008; MetroVancouvert, 2009; Azapagic, 2003; Perry et al., 2011; Cuthbertson et al., 2011; Linton, 2007). There are different terms to name that like sSCM or green supply chain, both terms have the same meaning which is to search more cooperation among partnering companies in order to make the SC operational and to reach sustainable performance (Ageron et al., 2011).

There exist many guides talking about sustainable Supply Chain (sSC), for example "2016 future Supply Chain" (Global Commerce initiative and Capgemini, 2008) or "sustainable Supply Chain Logistics Guide" (MetroVancouvert, 2009) ; they furnish many proposals for greening your supply chain but there is a lack of specifications for their implementation.

Another difficulty in this research has been to find accurate indicators and data to evaluate the application of sSC. Indeed it can be found numerous information on sustainable indicators but a few of it is standardized.

One possible solution for sSCM implementation is to use data providing by PLM systems such as ERP and PDM. The advantage of PLM is to provide support for the integrated management of product related information through the entire product lifecycle and it stems from computer integrated manufacturing (CIM) and engineering data management (Schuh et al., 2008). The aim of integrating management of product is to overcome the existing organizational barriers and to streamline the value creation chain (Schuh et al., 2008).

In the next section a methodology of sSC using data contains in PLM systems is explained.

\section{$3 \quad$ Proposed Methodology}

The proposal resides in the definition of a methodology used to implement sSC by managing data in PLM software.

The methodology is based on lifecycle stage (Fig. 1): extraction of raw materials, design and production, packaging and distribution, use and maintenance, and disposal (Remmen et al., 2007). The appropriate identification of all lifecycle stages is necessary for the establishment or optimization of environmental policies (Tsoulfas and Pappis, 2006). Each stage is going to have its own indicators and actions to achieve sSC depending on its needs.

The methodology process is divided in four main steps:

1. Select sustainable indicators.

2. Find causes and actions for improving indicators value.

3. List and define needed data from PLM software.

4. Implement action and evaluate indicators. 


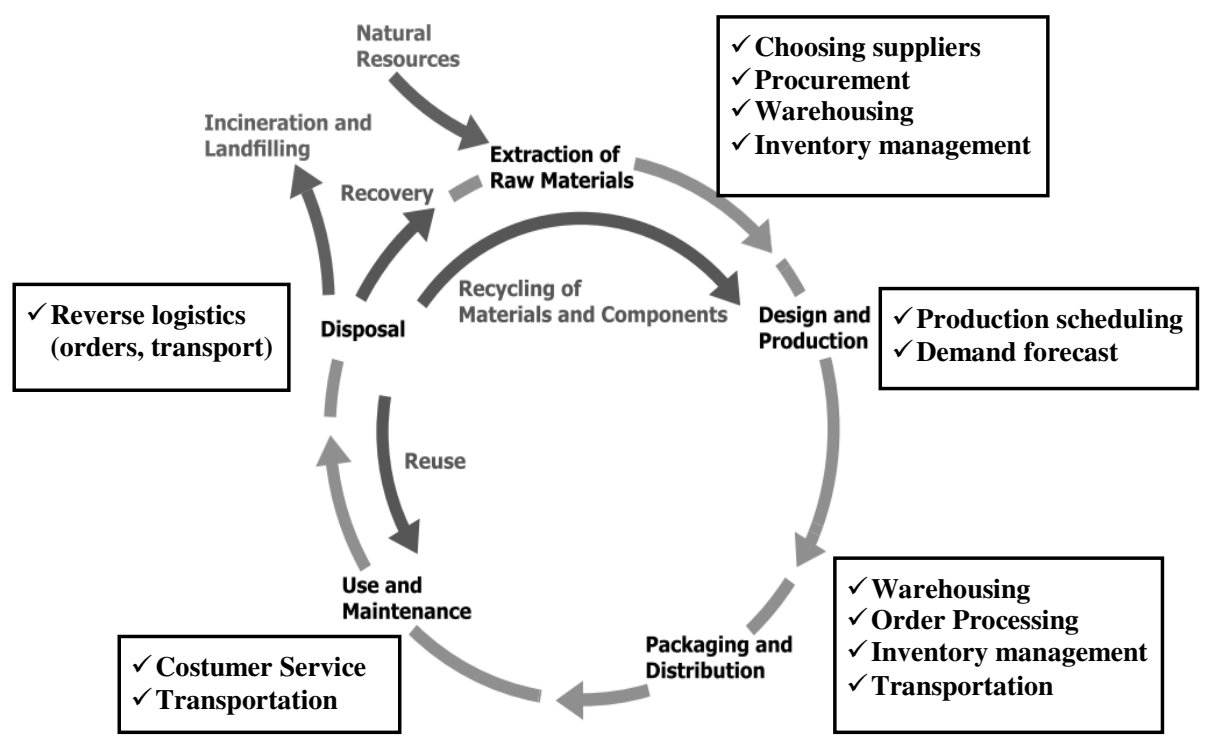

Fig. 1. Product lifecycle engineering vision (Remmen et al., 2007) and SCM activities in LC stage based on (Larson and Rogers, 1998)

\subsection{Step 1: Select Sustainable Indicators}

At first, it is needed to select proper performance indicators covering different aspects of sustainability (Krajnc and Glavic, 2005a); indicators should be quantitative whenever it is possible (Azapagic, 2003). The selection of sustainable indicators begins with the understanding of which elements of sustainable development should be considered (Krajnc and Glavic, 2005a).

Indicators are needed for companies because there is an old saying that you can't manage what you don't measure. When it comes to measuring business performance, management has to know whether a company is accomplishing established goals and objectives and how to compare it to others in the sector (Veleva, 2001a).

Indicators are normally numerical measures that provide key information about a system. "They go beyond simple data to show tends or cause-and-effect relationship" (Veleva, 2001b).

The main objectives of indicators are to raise awareness and understanding, to inform decision-making and to measure progress toward established goals.

There are many indicators about sustainable development at different levels (Veleva, 2001b). For this reason this paper focuses only on environmental company indicators useful to measure achievements of implementing sSCM.

- Energy used per unit of product (Azapagic, 2003; Azapagic and Perdan, 2000; Veleva, 2001b; Fernández-Sánchez and Rodríguez-López, 2010; Krajnc and Galvic, 2005b).

- Percent of raw materials from renewable resources (Veleva, 2001b). 
- Material used (Azapagic and Perdan, 2000; Fernández-Sánchez and RodríguezLópez, 2010; Veleva, 2001a; Veleva, 2001b).

- Waste generation before recycling (Azapagic and Perdan, 2000; Krajnc and Galvic, 2005b; Singh et al., 2009; Veleva, 2001a; Veleva, 2001b).

- GHG emissions per unit of product (Azapagic, 2003; Azapagic and Perdan, 2000; Krajnc and Galvic, 2005a; Krajnc and Galvic, 2005b; Singh et al., 2009; Veleva, 2001b).

These indicators are closely related to supply chain issues; GHG emissions are linked to transport, energy used is connected to warehousing, and finally material used and waste are connected with packaging among others.

\subsection{Step 2: Find Causes and Actions for Improving Indicators Value}

This step begins with a question; which are the causes of each indicator value? For example, in distribution stage; what cause GHG emissions related to supply chain? One really easy cause to find for the GHG emission is the transport (European Environement Agency, 2011). In this case is the transport between supplier and company.

This type of reflection is a essential step to move forward methodology; this step depends on company because each firm has its own process and its proper weak points in terms of sustainability.

After listing causes, it is the instant to propose actions to deal with these found causes. Actions will be based on cause-effect thinking and they will be various in each company because each firm owns its process and constraints. So it can find the most accurate form to enhance its sustainable indicators.

In the case of "Transport from suppliers" cause, possible actions are:

- Giving more importance to suppliers' proximity: local sourcing considers the trade-offs for remote sourcing between lower production cost and higher transport cost and $\mathrm{CO}_{2}$ emissions. It quickly shows that $\mathrm{CO}_{2}$ taxation needs to be quite severe to motivate more local sourcing (Global Commerce Initiative and Capgemini, 2008), but suppliers' proximity has to be bear in mind to find a balance between cost and $\mathrm{CO}_{2}$ emissions.

- Using eco-friendly transport: It is necessary to explore freight transport alternatives that consume less fossil fuel (for example, vehicles fuelled by biodiesel or using hybrid technologies) (MetroVancouvert, 2009).

- Improving accuracy in inventories and orders (MetroVancouvert, 2009): Better interoperability between PLM software and suppliers' information systems avoids errors in orders and wrong deliveries because product can be taken directly from the suppliers' PLM system (Le Duigou et al., 2011).

\subsection{Step 3: List and Define Needed Data from PLM Software}

In this section the solution applied is to link each action with the required data for monitoring the proposals and for integrating them in PLM software. PLM is related to 
a broad management concept which depends on the integration of multiple software components; the IT solution to support PLM results basically from the integration between Enterprise Resource Planning (ERP), Product Data Management (PDM) (Schuh et al., 2008).

This step consists in the extraction and specification of all the needed data to introduce necessary information to execute the action proposed. This data can exist or not in the current PLM software. If it exists the implementation will be easier. If it doesn't exist it is required to create it.

In our example, if we select "Giving more importance to suppliers' proximity" as action, the data needed are:

- Supplier code: integrated in ERP.

- Supplier location: integrated in ERP. The distance between suppliers' factory and company's warehousing can be easely calculate from that data.

Finally the nature of data has to be defined in order to standardize information from suppliers to customers. It is essential to bear in mind that the implementation of new policies and development of new management practices require the cooperation of partners to achieve a more effective approach (Tsoulfas and Pappis, 2006).

In our example, the data needed to be implemented are:

- Supplier code: dimensionless number needed for the identification of the different suppliers. It is an attribute which exists in ERP.

- Supplier location: GPS coordinates of the supplier's factory will be a new data added for every supplier in ERP.

\subsection{Step 4: Implement Action and Evaluate Indicators}

The last step is the implementation of the chosen actions. The monitoring of the results can be precisely manage through a dashboard based on the PLM data. The methodology closes-loop on step 2 when new targeted values of indicators are selected. New actions are decided and possibly new data in the PLM software are selected or created to manage the new actions.

\section{Conclusion}

The Sustainable Supply Chain has a relevant importance to create a sustainable business, but manufactures share the responsibility of this process with suppliers, consumers and others in the life cycle chain (Tsoulfas and Pappis, 2006). There are many ways to work for sustainability like product definition, manufacturing possibilities, logistic strategies and end life alternatives (Perry et al., 2011) but it is essential that main firms transfer across the whole supply chain the sustainability culture (Cuthbertson et al., 2011).

This article proposes a method to help companies to accomplish their environmental objectives. Based on the specific data of the enterprise enclosed in their PLM software, this methodology helps to monitor sustainable supply chain 
strategies. There are some improvements that could be insert in this methodology, like for short-term research, adding economic parameters to help in the eco-efficient decisions and adding for deciding the most appealing actions, or for medium-term, adding the social evaluation of the actions based on the specific information of the company.

\section{References}

Ageron, B., Gunasekaran, A., Spalanzani, A.: Sustainable supply management: An empirical study. International Journal of Production Economics, 1-15 (2011)

Azapagic, A.: Systems approach to corporate sustainability: A General Management Framework. System 81, 303-316 (2003)

Azapagic, A., Perdan, S.: Indicators of Sustainable Development for Industry: A General Framework. Process Safety and Environmental Protection 78(4), 243-261 (2000)

Cuthbertson, R., Cetinkaya, B., Ewer, G., Klaas-Wissing, T., Piotrowicz, W., Tyssen, C.: Sustainable Supply Chain Management. Strategy. Springer, Heidelberg (2011)

European Environment Agency. Laying the foundations for greener transport (2011)

Fernández-Sánchez, G., Rodríguez-López, F.: A methodology to identify sustainability indicators in construction project management-Application to infrastructure projects in Spain. Ecological Indicators 10(6), 1193-1201 (2010)

Global Commerce Initiative, \& Capgemini. 2016 Future Supply Chain (2008), http: / / www. futuresupplychain.com/

Ketikidis, P.H., Koh, S.C.L., Dimitriadis, N., Gunasekaran, A., Kehajova, M.: The use of information systems for logistics and supply chain management in South East Europe: Current status and future direction. Omega 36, 592-599 (2008)

Krajnc, D., Glavič, P.: How to compare companies on relevant dimensions of sustainability. Ecological Economics 55(4), 551-563 (2005)

Krajnc, D., Galvic, P.: A model for integrated assessment of sustainable development. Resources, Conservation and Recycling 43(2), 189-208 (2005)

Large, R.O., Gimenez Thomsen, C.: Drivers of green supply management performance: Evidence from Germany. Journal of Purchasing and Supply Management 17(3), 176-184 (2011)

Larson, P.D., Rogers, D.S.: Supply Chain Management: Definition, Growth and Approaches. Journal of Marketing Theory and Practice, Special Issue 6, 1-5 (1998)

Le Duigou, J., Bernard, A., Perry, N.: Framework for Product Lifecycle Management integration in Small and Medium Enterprises networks. Computer-Aided Design and Applications 8(4), 531-544 (2011)

Linton, J.D., Klassen, R., Jayaraman, V.: Sustainable supply chains: An introduction. Journal of Operations Management 25, 1075-1082 (2007)

MetroVancouvert. Sustainable Supply Chain Logistics Guide (2009), http: / / www . metrovancouver.org/smartsteps

Perry, N., Bernard, A., Bosch-Mauchand, M., Le Duigou, J., Xu, Y.: Eco Global Evaluation: Cross Benefits of Economic and Ecological Evaluation. In: Globalized Solutions for Sustainability in Manufacturing, pp. 681-686. Springer (2011)

Remmen, A., Jensen, A., Frydendal, J.: Life cycle management: a business guide to sustainability. United Nations Pubns. (2007)

Schuh, G., Rozenfeld, H., Assmus, D., Zancul, E.: Process oriented framework to support PLM implementation. Computers in Industry 59(2-3), 210-218 (2008) 
Seuring, S., Müller, M.: From a literature review to a conceptual framework for sustainable supply chain management. Journal of Cleaner Production 16(15), 1699-1710 (2008)

Sekhari, A.S., Hossain, S.A., Bouras, A., Santiteerakul, S.: Sustainable Supply Chain Management from the Perspectives of Risk Management. In: Proceedings of the APMS Conference, Italie (2010)

Singh, R., Murty, H., Gupta, S., Dikshit, A.: An overview of sustainability assessment methodologies. Ecological Indicators 9(2), 189-212 (2009)

Tsoulfas, G., Pappis, C.: Environmental principles applicable to supply chains design and operation. Journal of Cleaner Production 14(18), 1593-1602 (2006)

Veleva, V.: Using Sustainable Production Indicators to Measure Progress in ISO 14001, EHS System and EPA Achievement Track. Corporate Environmental Strategy 8(4), 326-338 (2001)

Veleva, V.: Indicators of sustainable production. Journal of Cleaner Production 9(5), 447-452 (2001) 